\section{LA INDEPENDENCIA DE LA FUNCIÓN JUDICIAL Y LA REFORMA DEL MECANISMO DE FUNCIONAMIENTO JUDICIAL EN CHINA*}

\author{
THE INDEPENDENCE OF THE JUDICIAL \\ FUNCTION AND THE REFORM OF THE \\ JUDICIAL OPERATION MECHANISM IN CHINA
}

A INDEPENDÊNCIA DA FUNÇÃO JUDICIAL
E A REFORMA DO MECANISMO DE
OPERAÇÃO JUDICIAL NA CHINA

\section{RESUMEN}

El presente trabajo aborda los problemas más importantes en el ejercicio de la función jurisdiccional en China, analizándose el carácter local y administrativo de la impartición de justicia en este país. Se analiza que la independencia del poder judicial no es la única forma de independencia de la función jurisdiccional, sino que ésta es posible a través de la implementación del ejercicio independiente de la función judicial por parte de los tribunales, según lo regulado en la Constitución y las leyes de China. La investigación recoge además las reformas del mecanismo de funcionamiento judicial desarrolladas en este país en los últimos años, en dos ámbitos fundamentales: la idependencia interna e independencia externa.

\footnotetext{
* Artículo de reflexión desarrollado por el autor en su ejercicio como profesor titular de Derecho Iberoamericano en la Universidad China de Ciencias Políticas y Derecho. El autor agradecer la colaboración de la profesora Lisy Alina Jorge Méndez de la Universidad de La Habana.

a. Doctor de Derecho Internacional Privado de la Universidad China de Ciencias Políticas y Derecho; Director del Instituto de Derecho de los países hispanohablantes de esta Universidad; Investigador visitante de la Universidad Autónoma de Madrid; investigador visitante de la Universidad Complutense de Madrid.
}

Pan Deng ${ }^{\text {a }}$ pandeng@vip.sina.com Fecha de recepción: 28 de octubre de 2015 Fecha de revisión: 19 de febrero de 2016 Fecha de aceptación: 20 de marzo de 2016

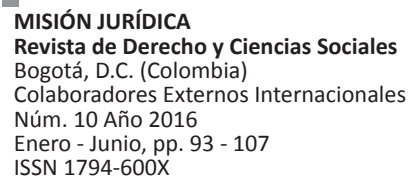




\section{PALABRAS CLAVES}

Independencia judicial, Reforma, Función jurisdiccional, Poder judicial, China. Corte de Circuito.

\begin{abstract}
This paper indicates the most important issues in the exercise of jurisdiction in China, analyzing its local and administrative characteristicsfor the impartation of justice in this country. It is evaluated that the independence of judicial power is not the only way of independence for its functioning.This is possible through the implementation of the independent exercise of jurisdiction by courts, according to the Constitution and other laws in China.. This paper also does research on the reforms of the mechanism of jurisdiction developed in China in the last few years, showing the two main areas: internal and external independence.
\end{abstract}

\section{KEY WORDS}

Independence of Jurisdiction, Reform, Functioning of Jurisdiction, Judicial Power, China, Circuit Courts.

\section{RESUMO}

Este artigo aborda os principais problemas do exercício da função judicial na China, suas características locais e administrativas, influenciando a justiça na China. Analisou-se que a independência do poder judicial não é a única forma de independência da função judicial, que se faz possível através da implementação do exercício independente da função judicial pelos tribunais, conforme regulamentado na Constituição e nas leis da China. A pesquisa também inclui reformas do mecanismo de operação judicial, desenvolvidas nesse país nos últimos anos, em duas áreas principais: independência interna e externa.

\section{PALAVRAS-CHAVE}

Independência judicial, Reforma - função jurisdicional - poder judicial - China - Tribunal de circuito.

\section{METODOLOGÍA}

En el desarrollo de la investigación se emplearon: el método histórico-jurídico en el estudio de la evolución de las instituciones analizadas, el método jurídico comparado para el examen de leyes foráneas con especial hincapié en las latinoamericanas; el método exegético para el estudio e interpretación de las normas jurídicas y el método de análisis y síntesis para el procesamiento de la literatura jurídica y científica.

\section{INTRODUCCIÓN}

La falta de independencia en la actividad judicial es la principal crítica formulada al sistema de justicia de China, tanto por los observadores internacionales como por la doctrina científica y los operadores jurídicos en el país. Sin duda, este grave problema dejó una gran huella en la imparcialidad de la autoridad jurisdiccional y el Poder Judicial. El mecanismo de funcionamiento de la jurisdicción, que presenta un carácter regional y un carácter administrativo, no se corresponde con los principios que rigen el ejercicio de la actividad jurisdiccional, principalmente, restringiendo el acceso de la población de escasos recursos a la justicia.

El informe del XVIII Congreso Nacional del Partido Comunista de China $(\mathrm{PCCh})^{1}$ celebrado en noviembre de 2012, se planteó impulsar integralmente la administración del país con arreglo a la ley, y profundizar en mayor medida la reforma del régimen judicial para mantener y mejorar el sistema judicial del socialismo con peculiaridades chinas, asegurando a los organismos judiciales y la fiscalía el ejercicio independiente y justo de sus atribuciones, en virtud de la ley.

A inicios de 2013, el Comité Central del Partido comenzó a implementar los cambios del sistema judicial, los que fueron incluidos como una de las tareas más importantes en la reforma de profundización integral, adoptada por la III Sesión Plenaria del XVIII Comité Central del Partido Comunista de China (CCPCCh) en noviembre de 2013. ${ }^{2}$ Desde diciembre de ese

1. El XVIII Congreso Nacional del Partido Comunista de China integrado por 2270 delegados elegidos por 40 circunscripciones, fue una importante reunión del máximo órgano de este Partido en el que se resolvió la sucesión de los máximos líderes para la segunda década del siglo XXI resultando así el más significativo cambio del liderazgo chino en varios años. El Congreso eligió a los miembros del Comité Central del Partido, su máximo órgano. De estos miembros del Comité Central, 24 forman una estructura más reducida que se reúne de manera periódica a lo largo del año, el Buró Político. A su vez, siete de los miembros del Buró Político forman el Comité Permanente. 
mismo año, nueve tribunales ${ }^{3}$ designados por el Tribunal Supremo comenzaron la reforma de esta área como una prueba que tendrá una duración prevista de dos años y que será extendida a toda China en el futuro no lejano.

\section{Los caracteres deficientes del funcionamiento judicial en China}

El fenómeno causado por el carácter local de la jurisdicción desemboca en la dependencia de los órganos jurisdiccionales a las autoridades locales, fenómeno existente en China, acentuándose en algunas áreas. Lo anterior se observan principalmente en las relaciones entre el tribunal y el Comité local del Partido ${ }^{4}$, el Congreso Popular local, el Poder Ejecutivo Local (el gobierno local), etc. Los asuntos financieros y los recursos humanos del tribunal son controlados por dichas autoridades locales.

El Partido, como principio, asume la responsabilidad de los asuntos relativos a la política de cuadros. El Comité del Partido de cada instancia regional está facultado para valorar y recomendar los candidatos para ser nombrados presidentes

\section{En ella estuvieron presentes 199 miembros titulares del Comité Central y 164 suplentes. También asistieron, sin derecho a voto, los miembros del Comité Permanente de la Comisión Central de Control Disciplinario y los camaradas responsables de los diversos sectores, así como algunos camaradas de base de entre los delegados al XVIII Congreso Nacional del Partido y varios expertos y eruditos.}

3. Dos de ellos cuatro son Tribunales Populares de nivel básico y cinco son Tribunales Populares intermedios. En el caso de los Tribunales Populares intermedios, son sujetos de reforma su propia instancia y los tribunales a él subordinados.

4. En China continental aún existen ocho partidos democráticos, pero en el contexto chino cuando se utiliza la expresión "Partido" se está haciendo referencia al Partido Comunista Chino. Los ocho partidos partidos son los que, fundados antes de la fundación de la República Popular China y dedicados a la realización de una república burguesa en China y, al mismo tiempo, apoyaron claramente al PCCh y reconocieron su derecho de dirección en el proceso de derrocamiento del rúgimen dictatorial del Guomindang (Partido Nacionalista) por parte del PCCh, y lograron subsistir despuús de la proclamación de la República Popular China. El sistema de cooperación multipartidaria y consulta política dirigido por el Partido Comunista de China (PCCh) es un sistema político básico de la República Popular China. Este sistema significa que el Partido Comunista de China es el único partido gobernante de la República Popular China, y que bajo la premisa de aceptar la dirección del PCCh, los ocho partidos democráticos tienen el status de partidos participantes en los asuntos estatales, cooperan con el PCCh y participan en el poder del Estado. de cada Tribunal, los presidentes de sus Salas, así como a los miembros de su Comité Judicial ${ }^{5}$. Estas autoridades judiciales son nombradas por la Asamblea Popular de la instancia regional a la que pertenecen o su Comité Permanente, previa propuesta del Partido, como se veía anteriormente. Sumado a lo anterior, en la práctica judicial el comité local del Partido interfiere en el desarrollo de los procesos judiciales.

De acuerdo con las disposiciones institucionales en China, el gobierno tiene el derecho a distribuir y controlar las finanzas públicas. La elaboración del presupuesto asignado al Poder Judicial es de competencia del gobierno y la aprobación de dicho presupuesto es competencia de la Asamblea Popular. Este mecanismo de distribución de la finanza pública fortalece la dependencia del Poder Judicial al gobierno local.

El tribunal a menudo conoce los conflictos de intereses entre dos partes y el resultado de las resoluciones judiciales traerá aparejado una redistribución de dichos intereses. Es decir, el órgano jurisdiccional dirimirá los conflictos que se sometan a su consideración y, teniendo varios intereses en conflicto, el órgano jurisdiccional con carácter local tenderá naturalmente a dar prioridad a los intereses locales. De las anteriores valoraciones se deriva que el órgano jurisdiccional local se ha convertido en un departamento de la autoridad local.

El carácter administrativo de la jurisdicción es aún más peligroso. En teoría, por la Ley de Organización del Tribunal ${ }^{6}$ y las leyes procesales ${ }^{7}$, los jueces constituyen el sujeto que ejerce el poder jurisdiccional $y$, naturalmente, son también la parte esencial y principal del órgano jurisdiccional. Teniendo en cuenta la función indispensable que desarrollan los jueces, tal como demuestran las experiencias del derecho comparado, estos no deben ser considerados como funcionarios públicos ordinarios. En la realidad china, el Presidente de Tribunal o de las Salas de Justicia, por sí mismo o mediante el departamento administrativo, se encarga del ingreso, asignación, evaluación, ascenso, permanencia y sanción

5. El Comité Judicial es una organización interna de cada Tribunal Popular que se encarga de discutir los casos importantes y complejos sometidos a su conocimiento, resumir las experiencias de la práctica judicial y otros asuntos judiciales. 
disciplinaria de los jueces a ellos subordinados. Inevitablemente, como consecuencia, estos últimos resolverán los procesos sometidos a su consideración según las valoraciones de sus superiores y del ente administrativo del Tribunal, sustituyendo las leyes, por la consideración de aquellos intereses administrativos.

La organización burocrática de cada tribunal conlleva a que la actividad judicial deba ser informada y auditada desde los niveles inferiores hasta el nivel superior de manera gradual. El presidente del tribunal tiene la atribución de examinar y verificar las resoluciones judiciales dictadas por los jueces que se le subordinan, cabe subrayar que esta facultad no se encuentra regulada en ninguna norma jurídica y se trata de proceso administrativo y no judicial. Este sistema tiene como objetivo supervisar y proteger el ejercicio correcto de la función jurisdiccional por parte de los jueces inferiores.

6. Zhonghua Renmin Gongheguo Renmin Fayuan Zuzhifa (se traduce literalmente Ley de la Organización del Tribunal Popular de la República Popular de China), adoptada en la $2^{a}$ reunión del Comité Permanente de la 5 a Asamblea Popular Nacional el 5 de julio de 1979, redactada en la $2^{a}$ reunión del Comité Permanente de la 6a Asamblea Popular Nacional el 2 de septiembre de 1983, en la 18 a reunión del Comité Permanente de la 6a Asamblea Popular Nacional el 2 de diciembre de 1986, y la 24 a reunión del Comité Permanente de la 10a Asamblea Popular Nacional el 31 de octubre de 2006. Se encuentra disponible en http://www.npc. gov.cn/wxzl/gongbao/2006-12/05/content_5354938.htm Las leys principales en ésta área son:

Zhonghua Renmin Gongheguo Xingshi Susongfa (se traduce litaralmente es La Ley Procesal Penal de la República Popular de China), adoptada en la $2^{a}$ reunión general de la $5^{a}$ Asamblea Popular Nacional el 1 de julio de 1979, redactada en la 4a reunión general de la $8^{\text {a }}$ Asamblea Popular Nacional el 17 de marzo de 1996, y la 5 a reunión general de la 11 a Asamblea Popular Naciona el 14 de marzo de 2012. Se encuentra disponible en http://www.gov.cn/flfg/2012-03/17/content_2094354.htm

Zhonghua Renmin Gongheguo Mingshi Susongfa (se traduce litaralmente es La Ley Procesal Civil de la República Popular de China), adoptada en la 4aㅡ reunión general de la 7ạ Asamblea Popular Nacional el 9 de abril de 1991, adoptada en la 30a reunión del Comité Permanente de la 10a Asamblea Popular Nacional el 31 de agosto de 2007 y 28a reunión del Comité Permanente de la 11a Asamblea Popular Nacional el 31 de agosto de 2012. Se encuentra disponible en http://www.gov.cn/ flfg/2012-09/01/content_2214662.htm

7. Zhonghua Renmin Gongheguo Xingzheng Susongfa (se traduce litaralmente es La Ley Procesal Administrativa de la República Popular de China) adoptada en la 2a reunión general de la 7a Asamblea Popular Nacional el 4 de abril de 1991, y 11a reunión del Comité Permanente de la $12^{a}$ Asamblea Popular Nacional el 1 de diciembre de 2014. Se encuentra disponible en http://www. gov.cn/flfg/2006-10/29/content_1499268.htm y http://www. npc.gov.cn/npc/xinwen/2014-11/02/content_1884662.htm
Todos los jueces, ya sea integrando un tribunal unipersonal o como miembro de un tribunal colegiado, poseen la misma competencia jurisdicción para conocer de los casos y dictar resoluciones judiciales, $\mathrm{y}$ deben subordinarse a la ley y no a otros integrantes del tribunal o a sus superiores. Una de las diferencias más significativas entre la actividad administrativa y la actividad judicial es la necesidad de un sistema de examen y verificación. Mientras en la primera, su existencia a menudo resulta útil, en la segunda la existencia de este fenómeno no es correcta. Las resoluciones judiciales dictadas por los jueces inferiores deben ser informadas y presentadas a sus directivos administrativos, desde el Vice-Presidente de Sala hasta su Presidente y desde el Vice- Presidente del Tribunal hasta el Presidente de dicho órgano. Este sistema de examen y verificación de las decisiones jurisdiccionales se confunde con la manera de gobierno de los asuntos administrativos. Esta confusión trae aparejado que, conjuntamente con el ejercicio de la autoridad administrativa que les es consustancial, los presidentes, tanto de Salas como de Tribunal, ejercen la facultad de supervisión y terminan ejercitando la función jurisdiccional indirectamente.

En la Ley de Organización del Tribunal se establece que los Presidentes de Sala o de Tribunal pueden ejercer la función jurisdiccional directamente $y$, en consecuencia, conocer casos concretos como presidentes de un tribunal colegiado. No obstante, en la realidad práctica, al ocupar dichos cargos ellos se enfrentan diariamente a las cuestiones administrativas y conocen muy pocos procesos de manera directa. El Tribunal Supremo Popular de la República Popular China ha subrayado repetidamente que el examen y la verificación del Presidente de Sala o de Tribunal no debe cambiar la decisión de juez, pero la fuerza y autoridad del Presidente afecta objetivamente la determinación de los jueces. Teóricamente el desarrollo del proceso ha de ser horizontal pero eventualmente se convierten en un proceso vertical de informes de abajo hacia arriba, y las relaciones entre los jueces que deben ser igualdad se convierten en relaciones de obediencia cuasi administrativas.

En la actualidad china se ha logrado el consenso de que el carácter local y administrativo de la 
jurisdicción es el principal problema que afecta el ejercicio apropiado y efectivo de ésta y además constituye una deficiencia grave que causa su injusticia y falta de independencia.

\section{2. "El Poder Judicial " en el contexto chino}

El objetivo principal de la reforma judicial es resolver los problemas más acuciantes que existen en la práctica judicial, y el motivo básico de la constitución del nuevo mecanismo de funcionamiento de la jurisdicción es mantener el ejercicio independiente de las funciones de los órganos judiciales. Se ha sugerido que la independencia del Poder Judicial es la única o la manera fundamental de erradicación del carácter local y administrativo de la jurisdicción, pero esta resulta incompatible con la política de China y no se ajusta al contexto político de este país.

La teoría de independencia del poder judicial nació en el período de la ilustración burguesa occidental y fue perfeccionada por MONTESQUIEU. ${ }^{8}$ En aquella época, el monarca controlaba el poder legislativo, el poder administrativo y el poder judicial en su reino ${ }^{9}$. MONTESQUIEU señaló que si el Poder Judicial y el Poder Ejecutivo se concentraban en manos de la misma persona o la misma institución, o el Poder Judicial no se encontraba separado del Poder Legislativo, no existiría libertad ${ }^{10}$. Si se producía la fusión del poder judicial y el poder legislativo, la vida y la libertad de los ciudadanos serían pisoteadas, y el juez tendría el poder para suprimir a otros.

Con la victoria de la revolución burguesa, el nuevo sistema político de marco institucional que se ha establecido en muchos países, sigue la doctrina de la separación de poderes, teniendo como base esta teoría. Los tres poderes se ejercen por diferentes autoridades, correspondiendo al parlamento, el presidente (o el gabinete), y el tribunal, existiendo un balance y un sistema de coerción mutua entre ellos ${ }^{11}$.

8. MONTESQUIEU, El espíritu de las leyes. Madrid, Biblioteca Auxiliar del Jurisconsulto y Publicista, 1845.

9. Se habla en esta época de un Estado Jurisdiccional en el que el Monarca era titular de todo el podery donde el principal momento de creación del Derecho es la decisión judicial particular que hace este monarca. Vid. FIORAVANTI, Maurizio. EN: Maurizio FIORAVANTI et al. (coordinador). El Estado moderno en Europa. Instituciones y Derecho (traducción castellana de M. Martínez Neira. Madrid, Editorial Trotta, 2004, pp. 18-20.
Aunque la independencia judicial tiene su origen en la doctrina de la separación de poderes, ello no quiere decir que sólo bajo la "separación de poderes" puede existir un poder judicial independiente, los dos no son inseparables. Fundamentalmente, la actuación independiente del poder judicial consiste en el ejercicio independiente de su función, o sea, no pueden confundirse la función legislativa, la función administrativa y la función judicial, ni pueden sustituir una a la otra ${ }^{12}$.

Por lo tanto, si existe una clara distinción entre la función legislativa, la función administrativa y la función judicial, y no sustituyen las unas a las otras, significa que se ha alcanzado el requisito formal de la independencia judicial. Con este análisis, tanto en el mecanismo político de la separación de los tres poderes, como en el arreglo institucional con la combinación de los poderes legislativo y ejecutivo, se puede cumplir con el requisito formal de la independencia judicial.

Desde la perspectiva del derecho comparado, la independencia del poder judicial ya no es simplemente un arreglo político institucional, sino que va más allá, se le otorga el carácter de principio básico de la administración de justicia e idea nuclear para la organización del funcionamiento del Poder Judicial. $\mathrm{Su}$ esencia consiste en asegurar que los órganos jurisdiccionales puedan ejercer sus funciones independientemente. Esto se puede verificar en las normas constitucionales, en los códigos y leyes, así como en los diseños institucionales existentes en los distintos países.

10. Entendido en el ámbito del derecho público el poder judicial ha sido entendido como un poder soberano, como una manifestación de la soberanía nacional. Vid. MORTARA, Lodovico. Lo Stato moderno e la giustizia. Napoli, Edizioni Scientifiche Italiane, 1992, p. 31 y ss.

11. Algunas valoraciones doctrinales niegan al poder judicial la condición de verdadero poder y plantean que el constitucionalismo moderno reconoce solos dos poderes: el legislativo y el ejecutivo. Vid. PEDRAZ, Ernesto. Constitución, jurisdicción y proceso. Madrid, Ediciones Akal, 1990, p. 29.

12. BORDALI SALAMANCA, Andrés. "La doctrina de la separación de poderes y el poder judicial chileno". EN: Revista de Derecho de la Pontificia Universidad Católica de Valparaíso, Valparaíso, Chile, 1er Semestre 2008, p. 197. 
La Ley Fundamental de la República Federal de Alemania ${ }^{13}$ establece en su artículo 97.114 que los jueces serán independientes (unabhangig) y sólo estarán sometidos a la ley. En la Constitución Política de la Federación de Rusia ${ }^{15}$ se define en su artículo 118.1 que la justicia será administrada en la Federación Rusa solo por los Tribunales, y en su artículo 121.2, que las funciones de los jueces no pueden ser cesadas o suspendidas, sino de acuerdo a las reglas y sobre las bases establecidas por la Ley Federal. El artículo 76 del texto constitucional de Japón ${ }^{16}$ establece que el poder judicial será ejercido exclusivamente por la Corte Suprema y los tribunales inferiores, de acuerdo con lo establecido por ley. No existirán tribunales extraordinarios, y ningún órgano del poder ejecutivo tendrá funciones judiciales definitivas. ${ }^{17}$

Este criterio encuentra también expresión en los países de Latinoamérica. México constituye

13. La Ley Fundamental para la República Federal de Alemania (en alemán: Grundgesetz für die Bundesrepublik Deutschland) es el nombre que recibe la Constitución de la República Federal de Alemania. Fue aprobada el 8 de mayo de 1949 en la ciudad de Bonn, firmada por los Aliados occidentales el 12 de mayo, y finalmente promulgada el 23 de mayo de 1949. Su ámbito de aplicación (en alemán: Geltungsbereich) originalmente fue sobre los territorios de la llamada "Trizona", en lo que después sería conocido como Alemania Occidental. Por el contrario, no incluyó el territorio de Berlín Oeste.

El legislador utilizó la expresión "Ley Fundamental" en vez de "Constitución", en parte por el deseo de marcar el texto con cierto carácter de provisionalidad, contando con que parte de Alemania había quedado separada por el telón de acero, y que por ello, una porción de la nación no quedaba sometida a la norma suprema.

14. Artikel 97

(1) Die Richter sind unabhängig und nur dem Gesetze unterworfen.

(2) Die hauptamtlich und planmäßig endgültig angestellten Richter können wider ihren Willen nur kraft richterlicher Entscheidung und nur aus Gründen und unter den Formen, welche die Gesetze bestimmen, vor Ablauf ihrer Amtszeit entlassen oder dauernd oder zeitweise ihres Amtes enthoben oder an eine andere Stelle oder in den Ruhestand versetzt werden. Die Gesetzgebung kann Altersgrenzen festsetzen, bei deren Erreichung auf Lebenszeit angestellte Richter in den Ruhestand treten. Bei Veränderung der Einrichtung der Gerichte oder ihrer Bezirke können Richter an ein anderes Gericht versetzt oder aus dem Amte entfernt werden, jedoch nur unter Belassung des vollen Gehaltes.

15. La Constitución de la Federación de Rusia es la ley fundamental de Rusia. Fue adoptada por referéndum el 12 de diciembre de 1993. Entró en vigor el 25 de diciembre de 1993 en el momento de su publicación oficial. Sustituyó a la anterior Constitución de la República Socialista Federativa Soviética de Rusia (RSFSR) del 12 de abril de 1978 - inspirada en la Constitución de la Unión Soviética de 1977 - después de la crisis constitucional rusa de 1993.

16. La Constitución de Japón es el documento legal refundador del Imperio japonés, tras su derrota militar en la Segunda uno de los países latinoamericanos en los que de manera más acentuada se expresa la separación de poderes, sin embargo no existe una expresión directa a la "independencia del poder judicial" en todo su texto constitucional. Al inicio de su título tercero sobre el Poder de la Federación, el artículo 49 establece que el Supremo Poder de la Federación se divide para su ejercicio en legislativo, ejecutivo y judicial. No podrán reunirse dos o más de estos poderes en una sola persona o institución. Más adelante, en el Capítulo IV de dicho título nombrado "del Poder Judicial", se prevé detalladamente la composición, organización, atribuciones y funcionamiento del poder judicial.

En la Constitución de la República del Ecuador, también denominada habitualmente como Constitución Política del Ecuador, cuando se regulan las atribuciones de las autoridades públicas, se utiliza el término "función" reemplazando el vocablo "poder". Los organismos y dependencias de las funciones legislativa, ejecutiva y judicial integran principalmente el sector público de su país. ${ }^{18}$ En su artículo 199 esta propia norma regula que los órganos de la Función Judicial serán independientes en el ejercicio de sus deberes y atribuciones. Ninguna función del Estado

Guerra Mundial en 1945. La constitución, también denominada la Constitución de la Paz o la Constitución Posguerra es famosa por la renuncia del derecho a la guerra que figura en el artículo 9 y, en menor medida, por la disposición de jure de la soberanía popular en relación con la monarquía.

La constitución proporciona un sistema parlamentario de gobierno y garantías de ciertos derechos fundamentales. En este marco, el Emperador de Japón es "el símbolo del Estado y de la unidad de la nación" y tiene un rol puramente ceremonial, sin tener ninguna soberanía. A diferencia de otros monarcas, no es el jefe de estado,1 aunque reciba el tratamiento como si lo fuese. La constitución fue redactada por un equipo de unos veinte estadounidenses durante la ocupación aliada que siguió a la Segunda Guerra Mundial, en una misión que se mantuvo en secreto hasta los años 1970.2 Se pretendía que reemplazase el sistema de la monarquía absoluta militarista por una forma de democracia liberal. Actualmente, es un documento rígido y no se ha hecho ninguna enmienda desde su adopción.

\section{7. https://es.wikisource.org/wiki/Constitución_del_Japón}

18. Según el mismo texto constitucional, los organismos electorales, los organismos de control y regulación, las entidades que integran el régimen seccional autónomo, las personas jurídicas creadas por acto legislativo seccional para la prestación de servicios públicos, junto con los organismos y entidades creados por la Constitución o la ley para el ejercicio de la potestad estatal, para la prestación de servicios públicos o para desarrollar actividades económicas asumidas por el Estado, también son partes del sector público. 
podrá interferir en los asuntos propios de aquellos. Los magistrados y jueces serán independientes en el ejercicio de su potestad jurisdiccional, aun frente a los demás órganos de la Función Judicial; solo estarán sometidos a la Constitución y a la ley.

De forma similar en la norma constitucional de Colombia, se reconoce la existencia de "Poder Público", y este es dividido en tres partes, ${ }^{19}$ pero no aparecen la definición de poder legislativo, poder administrativo o poder judicial. En este sentido se adopta la expresión más amplia de "Rama" para sustituir la de "Poder". En esta Constitución se regula la independencia en la toma de decisiones dentro de la administración de justicia, en razón de que el problema no radica en la independencia del poder judicial o la independencia de los órganos judiciales, sino que esta constituye un medio para garantizar la justicia de las resoluciones judiciales definitivas.

El tipo de sistema político de un país es adoptado en dependencia de sus condiciones nacionales y su historia. China es el típico país en el que existe una combinación de los poderes legislativo y ejecutivo. En concreto, la forma institucional del sistema de la Asamblea Popular constituye la esencia del sistema político de China.

En este sistema, los órganos a través de los cuales el pueblo ejerce el poder del Estado son la Asamblea Popular Nacional ${ }^{20}$ y las asambleas

19. El artículo 113 de la Constitución Política de Colombia comienza con: son Ramas del Poder Público, la legislativa, la ejecutiva, y la judicial.

20. La Asamblea Popular Nacional (APNRPC) es el máximo órgano legislativo de la República Popular China. Por influencia de la traducción convencional al inglés de esta institución National People's Congress, a veces se utiliza también en español el nombre Congreso Popular Nacional.

Formada por alrededor de 3000 diputados, que se reúnen una vez al año en el Gran Salón del Pueblo de Pekín, los miembros de la APN son elegidos por un periodo de cinco años. La composición de la asamblea elegida en 2013 tenía 2987 diputados y constituyó la XII Asamblea Popular Nacional, cuyo mandato finalizó en el año 2018. De entre los diputados de la APN, un grupo más reducido en torno a 150, forman el Comité Permanente de la Asamblea Popular Nacional, que se reúne de manera habitual y se encarga de las actividades legislativas rutinarias.

Además del poder legislativo, la Constitución de la República Popular China otorga a la APN otros tres poderes: El "poder de elegir, decidir y destituir a los integrantes o dirigentes de los órganos supremos del Estado", el "poder de decisión en los asuntos importantes del Estado" y el "poder de supervisión sobre los otros órganos supremos del Estado". populares de los diversos niveles locales, sus miembros son elegidos de acuerdo al principio de la representación proporcional. Los órganos estatales administrativos, judiciales y de otros tipos se conforman por la asamblea popular de sus respectivas instancias. La relación entre las Asambleas y demás órganos estatales radica en que estas últimas toman decisiones que después serán acatadas por dichos órganos y las asambleas tienen además la facultad de supervisar la ejecución por estos desarrollada.

$\begin{array}{ccccc}\text { Como } & \text { consecuencia de } & \text { dicho } & \text { sistema } \\ \text { político } & \text { establecido } & \text { en } & \text { la } & \text { norma }\end{array}$ constitucional ${ }^{21}$, concretamente regulado en el artículo 128 de la Constitución de la República Popular China ${ }^{22}$, el Tribunal Supremo responde ante la Asamblea Popular Nacional y su Comité Permanente, así como los Tribunales locales responden ante los órganos del poder del Estado que los han instituido, las asambleas populares de los diversos niveles locales de sus correspondientes instancias.

China no practica y no practicará la separación de poderes, la independencia del poder judicial no tiene ningún espacio institucional en China. Sin embargo, esto no significa que los tribunales chinos no tengan independencia. Por el diseño del sistema político de este país, los órganos estatales con distintas funciones y atribuciones, funcionan independiente y responsablemente dentro del ámbito de sus competencias. En relación con los órganos jurisdiccionales, el artículo 126 del Texto Constitucional enfatiza

21. La constitución de la República Popular China se establece en su artículo 101 que las asambleas populares locales de los diversos niveles eligen los gobernadores y vicegobernadores, el presidente del tribunal popular de su correspondiente instancia. Según los artículos 62.7 y 63.4, la Asamblea Popular Nacional tiene la facultad de elegir y destituir al Presidente del Tribunal Popular Supremo. En el artículo 67, se establece que el Comité permanente de la Asamblea Popular Nacional ejerce la función de supervisar la labor del Tribunal Popular Supremo y nombrar o destituir, a propuesta del Presidente del Tribunal Popular Supremo, a sus vicepresidentes, jueces y miembros del jurado así como al Presidente del Tribunal Militar.

22. Zhonghua Renmin Gongheguo Xianfa(se traduce litaralmente es La Contitución de la República Popular de China), adoptada en la $5^{a}$ reunión general de la $5^{\underline{a}}$ Asamblea Popular Nacional el 4 de diciembre de 1982, redactada en la $1^{a}$ reunión general de la 7ạ Asamblea Popular Nacional el 12 de abril de 1988, en la $2^{a}$ reunión general de la 6a Asamblea Popular Nacional el 29 de marzo de 1993, y la 2a reunión general de la 10a Asamblea Popular Naciona el 14 de marzo de 2004. Se encuentra disponible en http://www.gov.cn/test/2005-06/14/content_6310_2.htm 
que los tribunales ejercen independientemente la función jurisdiccional de acuerdo con lo previsto por la ley, sin admitir la injerencia de ningún órgano administrativo, organización social o individuo ${ }^{23}$.

En el fondo de la teoría de la separación de poderes, la independencia del poder judicial es una forma de independencia. La independencia de la función judicial en el sistema de la asamblea popular es otra forma de independencia. Dos formas que tienen el mismo objetivo, asegurar que el juez se encuentre sometido a la ley y garantizar la justicia social.

Por lo tanto, la independencia de los órganos jurisdiccionales existe en el sistema del funcionamiento de poderes públicos de China. En la reforma del régimen judicial, no es necesario esperar a la creación de un sistema de "independencia del poder judicial" para resolver todos los problemas que en la práctica presenta el ejercicio independiente de la administración de justicia. La ruta factible que podemos trazar es la implementación del ejercicio independiente de la función judicial por parte de los tribunales, según lo previsto en la ley, lo que ya se encuentra plasmado en la Constitución y se ha mencionado en el informe del XVIII Congreso Nacional del PCCh.

\section{La reforma de independencia externa}

Sin duda, la teoría de la separación de poderes que establece que los poderes legislativo, ejecutivo y judicial tienen igual jerarquía, garantiza la independencia externa del poder judicial en lo institucional, pero eso no significa que la independencia judicial sólo exista en el sistema de separación de poderes, esta sería una concepción rígida sobre el asunto. En los países socialistas, por ejemplo en China, se implementan la división y la limitación de atribuciones como principios fundamentales de la distribución del poder. De acuerdo con esta lógica, la función judicial deriva de la función legislativa y obtiene independencia

23. Para DUGUIT la función jurisdiccional consiste en hacer constar la existencia de una regla de derecho o de una situación de derecho. El Estado se ve obligado a intervenir cuando la regla de derecho ha sido violada, disponiendo el Estado las medidas necesarias para asegurar el respeto debido a su decisión. Vid. DUGUIT, Leon. Manual de Derecho Constitucional, Granada, Editorial Comares, 2005, p. 79 y ss. relativa desde el momento mismo de su creación. Es muy difícil que la función legislativa intervenga en la función judicial por el carácter de aquella. En cuanto a la relación entre la función ejecutiva y la función judicial, dado que las dos emanan de la función legislativa, y tienen el mismo nivel, los conflictos entre ellos no son muy graves en el marco del ejercicio del poder.

Otro tema importante, y que es urgente resolver, es la relación entre los órganos judiciales y la dirección del Partido. Desde la fundación de la República Popular China en 1949 hasta la actualidad, en el país ha existido la opinión de que la independencia de los órganos judiciales se contrapone a la dirección del Partido. Es esta la principal razón por la cual no se han logrado grandes avances en materia de reforma judicial, en un periodo tan largo de tiempo.

De hecho, no hay justicia alguna que pueda ser totalmente independiente de la política ${ }^{24}$. Incluso en los países occidentales, las distintas fuerzas políticas siempre intervienen abierta o encubiertamente en el funcionamiento del poder judicial. Por ejemplo, en los Estados Unidos, los gobiernos que se suceden desean tener la oportunidad de nombrar como jueces de la Corte Suprema a integrantes de su partido para, de esta forma, incidir en la administración de justicia.

En China, la Constitución y las leyes son creadas por el pueblo dirigido por el Partido y reflejan la voluntad y los intereses de ambos. El método de dirección del Partido necesita garantizar el ejercicio independiente de la función judicial, de

24. Posición diferente sostiene IBÁÑEZ para quien la jurisdicción, según como está concebida en los sistemas constitucionales modernos, requiere que el juez sea tercero frente a las demás instancias de poder, debe tener autonomía política y estar exento de toda subordinación, siendo esto lo que lo hace independiente para la aplicación igualitaria de la ley al caso concreto como sujeto imparcial. Vid. ANDRES IBÁÑEZ, Perfecto. Poder judicial y juez en el Estado constitucional de Derecho. El sistema del Consejo en La experiencia jurisdiccional: Del Estado legislativo de Derecho al Estado constitucional de Derecho. Madrid, Consejo General del Poder Judicial, 1999, p. 18.

25. Deng Xiaoping, (1904 - 1997), natural de la provincia de Sichuan de China. El prominente político reformista chino, y el principal líder del Partido Comunista China (PCCh) entre 1978 y la década de 1980. Deng nunca fue formalmente principal jefe de Estado ni de Gobierno, pero fue el Presidente de la Comisión Militar Central de la República Popular China desde 1981 hasta 1989, y el líder de facto de la República. Desarrolló el «socialismo con características chinas», fue el padre de la reforma y apertura y la modernización socialista de China. 
conformidad con la ley. Ya en el año 1986, Deng Xiaoping ${ }^{25}$ indicó que el Partido no debe intervenir en las cuestiones relativas al ámbito judicial, las que deben resolverse según las normas jurídicas. Si el Partido interfiere demasiado en estos asuntos, ello no resulta favorable para la seguridad jurídica y contribuye a que la sociedad pierda confianza en las leyes. ${ }^{26}$ Esta idea posee consenso tanto entre los operadores jurídicos en China como entre los académicos chinos, después del XVIII Congreso Nacional del PCCh.

Por lo tanto, la reforma judicial en curso en el país no se aparta de las ideas de la dirección del Partido, sino que prueba la transformación del método de dirección de éste, abandonando el vicio enraizado en la tradición de que el liderazgo del Partido interviene en la solución de casos concretos. Las resoluciones para promover el Estado de Derecho ${ }^{27}$ regulan que los funcionarios serán criticados, mediante amonestaciones públicas, si influyen en las actividades judiciales o interfieren en un caso en particular. China está estableciendo un sistema para que a los funcionarios que interfieran en los procesos judiciales se les impongan deméritos o sean responsabilizados.

Se ha mencionado anteriormente en este artículo que la principal razón del carácter local de la jurisdicción está en la asignación de recursos financieros y la organización de los recursos humanos de los órganos jurisdiccionales, temas que han estado controlados por las autoridades locales en cada instancia. Las resoluciones que abordan la profundización integral de la reforma ${ }^{28}$ regulan el mecanismo para llevarla a cabo dicha en la administración de justicia e impulsan la gestión de los temas relativos al personal, los bienes y recursos materiales por parte de los tribunales y

26. Deng Xiaoping, Las Obras Escogidas de Deng Xiaoping (Volumen III), (1 ${ }^{a}$ edición, Beijing, 1993), p.163.

27. Resoluciones del Comité Central del Partido Comunista de China acerca de algunos problemas importantes relativos a promover el Estado de derecho, aprobadas el 28 de octubre de 2013 por la IV Sesión Plenaria del XVIII Comité Central del Partido Comunista de China.

28. Resoluciones del Comité Central del Partido Comunista de China acerca de algunos problemas importantes relativos a la profundización integral de la reforma, aprobadas el 12 de noviembre de 2013 por la III Sesión Plenaria del XVIII Comité Central del Partido Comunista de China. fiscalías locales inferiores al nivel de la provincia. Las resoluciones encargadas de promover el Estado de Derecho ${ }^{\underline{29}}$ regularon las reformas del régimen de administración del personal, los bienes y los recursos materiales de los órganos judiciales y el establecimiento de sistemas de atribución judicial, adecuadamente separados de la facultad de gestión administrativa judicial.

Debe tenerse en cuenta que, según el objetivo final de la reforma judicial, la facultad de gestión administrativa judicial debe ejercerse unificadamente por el Gobierno Central. El ejercicio de dicha facultad por parte de los gobiernos provinciales, autorizados por el Gobierno Central, sólo tiene un carácter transitorio por el principio de progresividad de la reforma judicial.

Además, hay que señalar que cuando el Tribunal Popular rinda informe a la Asambleas Populares de su instancia, dentro del proceso de que estas se deshagan del control de los asuntos de recursos humanos y financieros, puede ocurrir que dichas asambleas locales obstaculicen ésta reforma aprovechando sus facultades de deliberación y aprobación respecto a dicho informe. Aunque resulta raro, este fenómeno ha ocurrido en la práctica y pudiera repetirse en el futuro.

Por esta razón, se hace necesario explicar la expresión legal "responder", contenida en el artículo 128 de la Constitución de la República Popular China. "Responder ante los órganos del Poder del Estado" no necesariamente significa asumir la responsabilidad política, sino aceptar la supervisión holística por parte de tales órganos. Con base en esto, cuando la asamblea popular local veta el informe del tribunal de su instancia, el presidente no asume la responsabilidad política por ello. En concreto, si el veto de la Asamblea recae sobre el trabajo realizado en el pasado, ello significa que esta está utilizando su facultad de supervisión o propuesta; por el contrario si el veto recae sobre el plan de futuro de trabajo del tribunal, ello implicará que el presidente deberá modificar o perfeccionar su

29. Resoluciones del Comité Central del Partido Comunista de China acerca de algunos problemas importantes relativos a promover el Estado de derecho, aprobadas el 28 de octubre de 2013 por la IV Sesión Plenaria del XVIII Comité Central del Partido Comunista de China. 
plan y la asamblea tendrá derecho nuevamente a deliberar y votar este nuevo plan.

Otra reforma que está avanzando en esta área es el restablecimiento del sistema de competencia judicial. Durante décadas, la competencia jurisdiccional coincidía completamente con las divisiones administrativas. El sistema de que los órganos ejecutivos y judiciales pertenezcan a la asamblea popular local de su misma instancia es muy beneficioso para dichas autoridades locales, quienes pueden interferir en la solución de los casos, según sus intereses, y construyendo la ley para conseguirlo, lo que redunda en proteccionismo local. Un considerable número de los líderes locales considera a los tribunales como sus propios departamentos subordinados y aplican las políticas locales en desafío a la Constitución y las leyes. Como consecuencia de lo anterior, el restablecimiento del sistema de competencia judicial, adecuadamente separados de las divisiones administrativas, al que se hace referencia tanto en las resoluciones de la profundización integral de la reforma como en las resoluciones de promover el Estado de derecho, se convierte en una medida importante de la reforma judicial.

Se han llevado a cabo experiencias piloto en tres direcciones, las Cortes de circuito del Tribunal Popular Supremo, los tribunales con competencia jurisdiccional de transdivisiones administrativas y los tribunales de propiedad intelectual.

El Tercer Tribunal Popular Intermedio de Shanghái surgió el día 28 de diciembre 2014 y es el primer tribunal con competencia jurisdiccional de transdivisiones administrativas ${ }^{30}$. En su primera fase piloto, tiene competencia para conocer en primera instancia los casos administrativos en los que figure como demandado el Gobierno de Shanghái, para conocer en segunda instancia los casos administrativos en los que concurra como parte recurrente un órgano administrativo municipal, y para ventilar los casos penales en los que la parte acusadora sea la Tercera Rama de la Fiscalía Popular de Shanghái. Análogamente, dos

30. A diferencia de este tribunal intermedio, otros dos tribunales populares intermedios de este municipio tienen competencias jurisdiccionales que se corresponden, en el caso de uno de ellos con siete tribunales del mismo número de subdivisiones administrativas y el otro con diez tribunales de igual número de subdivisiones administrativas, todas de Shanghái. días más tarde, fue fundado el Cuarto Tribunal Popular Intermedio de Beijing. Además de los casos administrativos, el de Beijing también tiene competencia jurisdiccional para conocer los conflictos relativos a préstamos financieros, de seguro, asuntos comerciales relacionados con Hong Kong, Macao, Taiwán y los países extranjeros, así como casos sobre la protección ambiental y la seguridad de alimentos y medicamentos.

El 31 de agosto de 2014, la 10ª reunión del Comité Permanente de la $12^{\text {a }}$ Asamblea Popular Nacional decidió que se crearan los Tribunales de la Propiedad Intelectual en Beijing, Shanghái y Guangzhou. El 3 de noviembre del mismo año, el Tribunal Supremo definió claramente las competencias jurisdiccionales de dichos tribunales. Además de la jurisdicción territorial correspondiente, el Tribunal de la Propiedad Intelectual de Guangzhou también tiene competencia en primera instancia para conocer los casos de esta área de otras ciudades de su provincia y el de Beijing tiene la jurisdicción exclusiva de los casos administrativos sobre la propiedad intelectual.

Según lo regulado en las resoluciones de promover el Estado de Derecho, los días 28 y 31 de enero de 2015 fueron creadas la Primera y la Segunda Corte de Circuito del Tribunal Supremo respectivamente. Como ramas del Tribunal Supremo las dos Cortes de Circuito tienen la misma competencia jurisdiccional que éste para conocer de los casos civiles, comerciales y administrativos en sus circuitos judiciales. La Primera Corte de Circuito, situada en la ciudad de Shenzhen, cercana al norte de Hong-Kong, tiene competencia sobre tres divisiones administrativas de nivel provincial localizadas al sur de China, y la Segunda Corte está situada en la ciudad de Shenyang, y tiene competencia respecto a tres provincias localizadas al noroeste de China.

En éstas tres direcciones, los cambios que se han realizado hasta el momento no abarcan todo el contenido de la reforma, son sólo una parte que se está aplicando de manera piloto. Por ejemplo, los Tribunales de Propiedad Intelectual surgieron primeramente en las tres regiones más desarrolladas económicamente y también en el área del conocimiento y de la innovación, contexto en el que se surgen más conflictos en esta materia. Por su parte, los tribunales intermedios de transdivisiones administrativas se fundaron en los dos municipios 
controlados directamente por el Gobierno Central, donde la estructura administrativa es más sencilla y existen menos niveles administrativos que los tienen otras divisiones de nivel provincial. En cuanto a las Cortes de Circuito del Tribunal Supremo, estas solo existen en seis de las treinta y un divisiones de nivel provincial de la Parte Continental China. Además de lo anterior, la jurisdicción en materia de la propiedad intelectual, de los asuntos marítimos, de la indemnización del Estado y otros, se conserva temporalmente en la sede del Tribunal Popular Supremo. No hay duda de que al desarrollarse las experiencias de dichas reformas en regiones y materias específicas, estas se replicarán y promocionarán rápidamente en toda China.

\section{La reforma de Independencia interna}

El ejercicio independiente de la función jurisdiccional requiere la existencia de independencia externa, o sea en cuanto a las relaciones con otras autoridades, y la vez independencia interna, aquella relativa a los jueces y que tiene lugar dentro del propio sistema de justicia. Su objetivo principal es garantizar que los jueces ejerzan sus atribuciones independientemente y desde la perspectiva del derecho internacional y el derecho comparado existe consenso en relación con el valor de este principio. Según el artículo segundo de los Principios Básicos Relativos a la Independencia de la Judicatura, los jueces resolverán los asuntos que conozcan con imparcialidad, basándose en los hechos y en consonancia con el derecho, sin restricción alguna y sin influencias, alicientes, presiones, amenazas o intromisiones indebidas, sean directas o indirectas, de cualesquier sector o por cualquier motivo ${ }^{31}$. La Ley Fundamental de la República Federal de Alemania establece en su artículo 97.1 que los jueces han der ser independientes y el artículo 230 regula que los jueces, en sus providencias, sólo estarán sometidos al imperio de la ley.

En la mayoría de los países, la independencia interna del órgano judicial no es básicamente

31. Principios básicos relativos a la independencia de la judicatura. Adoptados por el Séptimo Congreso de las Naciones Unidas sobre Prevención del Delito y Tratamiento del Delincuente, celebrado en Milán del 26 de agosto al 6 de septiembre de 1985, y confirmados por la Asamblea General en sus resoluciones 40/32 de 29 de noviembre de 1985 y 40/146 de 13 de diciembre de 1985. un problema, y las exigencias de la justicia han estado dirigidas esencialmente al diseño del procedimiento judicial. Sin embargo, la situación de China es diferente, aunque en el diseño chino del procedimiento judicial se establece la exigencia de garantizar la justicia, la independencia interna siempre ha sido una dificultad desconcertante para los jueces. De ello se deriva, que en la reforma del mecanismo de ejercicio de la función judicial, comparado con la "deslocalización", el problema de la independencia interna resulte de mayor importancia y significación. Dado que la falta de independencia interna se relaciona con la "administrativización" de la actividad judicial, la reforma judicial actual de China tiene como tema principal la eliminación de este problema.

Los objetivos de la reforma en ésta área, según "el programa de la reforma del mecanismo de funcionamiento como experimento", publicada el día 18 de octubre 2013 por el Tribunal Supremo son: implementar el despliegue integral del Gobierno Central en la profundización de la reforma del sistema judicial y de su mecanismo de trabajo; cumplir con los requerimientos de una justicia justa; establecer el modo de funcionamiento y ejercicio de la función jurisdiccional de conformidad con los principios judiciales; optimizar la asignación de recursos a los órganos judiciales; fortalecer el sistema de responsabilidad de los jueces principales y la corte colegiada en la atención a casos por ellos conocidos; mantener el principio de proceso independiente; satisfacer la demanda de la población de equidad y justicia en la mayor medida posible; mejorar la credibilidad del sistema judicial y establecer el imperio de la ley en toda la sociedad. Aunque, es de anotar, que el logro de estos objetivos mencionados depende del avance simultáneo de todo el conjunto de reformas relacionadas.

4.1 Responsabilidades en la gestión judicial de los presidentes de Tribunales y presidentes de Salas

El problema de administrativización que tiene lugar en el mecanismo actual de ejercicio de la función jurisdiccional, se encuentra principalmente en los límites poco claros entre los deberes de la gestión administrativa y los deberes judiciales de los presidentes de los Tribunales o las Salas. De acuerdo con los requisitos del programa de reforma del día 18 de octubre 2013, los presidentes, de 
conformidad con las disposiciones de la Ley de Organización de los Tribunales Populares y las leyes de procedimiento pertinentes, ejercerán las siguientes funciones judiciales:

a) supervisar las resoluciones judiciales firmes, de conformidad con la ley;

b) tomar decisiones en caso de recusación, preservación de la propiedad y otros asuntos sobre procesales de acuerdo con los límites de su autoridad y el procedimiento prescrito en la ley;

c) presidirá el comité judicial, la reunión de los jueces profesionales y la reunión conjunta de los jueces principales para discutir asuntos generales;

d) orientar la labor judicial de forma integral o especial de una manera macroscópica;

e) presidirá la comisión para el examen y la evaluación de los jueces para revisar su desempeño y evaluarlos de conformidad con las disposiciones de la ley judicial;

f) será responsable de organizar la elaboración de investigaciones con vistas a diseñar políticas judiciales que ayuden a mejorar la justicia, eficiencia y credibilidad pública del sistema de justicia, sobre la base de la información de la actividad jurisdiccional existente;

g) adoptar medidas para optimizar los procedimientos de transferencia interna de acuerdo a las circunstancias de su tribunal;

h) realizar el trabajo de gestión de otros asuntos relacionados directamente con la labor judicial.

Para mejorar la eficiencia de su desempeño, los tribunales van a explorar la posibilidad de ejercer una gestión centralizada de los asuntos administrativos, de la gestión de recursos humanos y de la gestión financiera mediante la creación de los cargos de asistente del presidente y de asistente de juez, quienes contribuirán con los presidentes y jueces en el manejo de dichos asuntos. De acuerdo a la ley, cuando los presidentes de tribunal o de sala realicen tareas de gestión administrativa, no deberán interferir con el ejercicio de la función jurisdiccional.

\subsection{Sistema de firma de los documentos judiciales}

La firma de los documentos judiciales constituye una facultad que simboliza y refleja la administrativización del mecanismo de funcionamiento de la actividad judicial en China y ha sido una enfermedad incurable durante muchos años. La determinación de a quién corresponde el derecho de firmar los documentos judiciales ha sido siempre foco de reformas pasadas, pero en la presente, éste sistema llegará a su fin.

De acuerdo con los requisitos previstos en el programa de reformas actual, el presidente de Tribunal o de Sala no debe firmar las resoluciones judiciales correspondientes a procesos en los que no han participado. En relación con los procesos seguidos de forma independiente por un juez de manera unipersonal, los documentos relativos al caso han de ser firmados directamente por aquel que lo conoció. En cuanto a los casos seguidos por los asistentes de los jueces de forma independiente, los documentos del proceso deben ser revisados y firmados por los jefes de cada tribunal colegiado. Los documentos relativos a procesos seguidos por tribunales colegiados, deben ser firmados conjuntamente por los jueces que se encargan del caso, por los demás jueces que integran el tribunal colegiado, y los jueces principales.

La razón de que se mantenga el procedimiento de que las resoluciones de los asistentes de jueces deban "ser revisadas y firmadas por otro juez " radica en el hecho de que estos solo tienen una parte de la facultad jurisdiccional.

4.3 Las conferencias conjuntas de los jueces principales y las conferencias de jueces profesionales

Después de la eliminación del sistema de examen, aprobación y firma de las resoluciones judiciales por parte de los presidentes de Tribunal y Sala, se hace necesario reorganizar los recursos humanos internos de los tribunales con el fin de resolver cuestiones jurídicas complejas.

Existen dos maneras de darle solución a este problema. La primera manera es que los presidentes de Tribunal y los presidentes de Sala dirijan directamente los tribunales colegiados, y la segunda forma consiste en que los miembros de los comités judiciales formen parte de los tribunales colegiados para conocer casos difíciles. Además resulta necesario crear otros dos sistemas, uno, mediante la reunión conjunta de los jueces principales y el otro, con la reunión de jueces profesionales para aglutinar la sabiduría colectiva, analizar, 
estudiar y discutir aquellos asuntos difíciles y buscarles solución.

Estos tipos de reuniones se han usado popularmente en la práctica judicial de los últimos años y esta nueva reforma los reconoce como un sistema. Cuando un juez actuando de forma unipersonal, o un juez principal de tribunal colegiado, conozca un caso complejo o difícil y encuentre problemas en la aplicación de ley u otros inconvenientes relacionados con la solución jurídica del caso, puede presentar este asunto a uno de estos tipos de reuniones. La conclusión de la discusión se registrará como referencia para la decisión final del juez, no siendo vinculante para este.

\subsection{Los Presidentes de los Tribunales y las Salas integran de manera directa los tribunales colegiados}

Aunque el sistema de que los presidentes de Tribunales y Salas pueden conocer directamente de casos como juez principal, se encuentra establecido en la Ley de Organización del Tribunal Popular, el modo actual en que se organizan los recursos humanos en la administración de justicia, refuerza el papel en la gestión administrativa de dichos presidentes. Ellos, normalmente, no conocen los casos de manera directa, sino que los conocen a la manera de "mantener estándares estrictos", desempañando la función de cuadros dirigentes y mediante el "examen" o "aprobación" de las resoluciones judiciales dictadas por los jueces que sí conocen el caso directamente.

La medida más importante en el presente programa de reformas será la "transferencia" de estos recursos humanos hacia puestos claves en donde conocerán el caso directamente. Los vicepresidentes de Tribunal, miembros del comité judicial, los presidentes y vicepresidentes de Salas deben ser parte de tribunales colegiados, como el juez principal, y conocer los casos directamente. En el caso de los tribunales colegiados cuyo juez principal no sea el presidente o vicepresidente de Tribunal o Sala, el juez principal será seleccionado de entre sus integrantes de acuerdo al que sea más profesional de estos. Con el fin de garantizar al juez principal y al resto de los jueces, cumplir eficazmente sus obligaciones judiciales, pueden ser enviados un cierto número de asistentes de juez y secretarios judiciales a asistir a los primeros en el ejercicio de sus funciones.
4.5. El tribunal colegiado integrado por miembros del comité judicial

Los jueces designados como miembros de los comités judiciales de cada tribunal son generalmente jueces superiores de excelente desempeño. De acuerdo con el actual programa de reformas, como miembros de los comités judiciales, además de presidir tribunales colegiados como su juez principal para conocer de casos y asistir las reuniones conjuntas de los jueces principales y las reuniones de jueces para discutir cuestiones legales, ellos también pueden conformar el "tribunal colegiado de los miembros del comité judicial" que estará compuesto de tres a siete personas y conocerá los casos importantes, difíciles y complejos.

\subsection{Sistema de responsabilidad de los jueces}

El establecimiento de un mecanismo de rendición de cuentas para los jueces es un importante contenido en ésta nueva reforma del mecanismo de funcionamiento de la actividad jurisdiccional. Partiendo de la premisa del ejercicio independiente de la función judicial de conformidad con la ley, los jueces deben asumir la responsabilidad de sus propias decisiones en cada caso concreto, lo que constituye una cuestión común para todos los países.

¿Qué tipo de responsabilidad deben asumir los jueces en relación a sus propios actos? Las resoluciones de la profundización integral de la reforma establecen el principio, según el cual quien conoce el caso es quien asume la responsabilidad de este. El programa de reforma establecido por el Tribunal Supremo, de acuerdo con la "unificación de derechos, responsabilidades y beneficios", ha definido claramente los diversos tipos de responsabilidades de los jueces, tribunales colegiados y sus miembros.

Se regula de manera específica la responsabilidad relativa a la ética profesional. En relación con esta, se prevé para los casos de jueces que violan las normas fundamentales de ética profesional, la amonestación y las conversaciones de advertencia, estos pueden además ser criticados públicamente o seriamente castigados de conformidad con las disposiciones disciplinarias y las leyes pertinentes, si las conductas son suficientemente graves. 
La responsabilidad disciplinaria. El Tribunal Popular Supremo ha formulado medidas específicas para la rendición de cuentas relacionadas con la responsabilidad de los jueces en los juicios.

La responsabilidad administrativa. La reforma requiere que los tribunales establezcan archivos de examen y evaluación de los jueces. De conformidad con lo dispuesto en las leyes sobre la judicatura, la Comisión de Examen y Evaluación de Jueces es responsable de guiar el proceso de evaluación de los jueces. El resultado de la evaluación se recoge en los archivos para el examen y la evaluación de los jueces, y constituye la base y referencia principal para identificar la cualificación profesional de estos, determinar su nivel de evaluación anual y la evaluación de la excelencia y promociones. Por otro lado, se establece el mecanismo de evaluación por un tercero, incluyendo la evaluación de los jueces en cuanto a su estilo de trabajo y la ética profesional de los participantes en el proceso y el público.

La responsabilidad penal. Si constituye un delito la acción u omisión llevada a cabo por el juez en ejercicio de su función jurisdiccional, será investigado penalmente de conformidad con las normas vigentes sobre la materia.

La responsabilidad pública. Toda la actividad judicial es accesible al público, de ahí que el comportamiento de los jueces es objeto de inspección pública y comentarios al respecto. Los medios de comunicación pueden también supervisar el comportamiento de los jueces. A pesar de que los jueces no son elegidos por la población, con excepción de los Presidentes de Tribunales, el resto puede ser castigado e incluso removido de su cargo debido a la insatisfacción pública en relación con su conducta.

\section{CONCLUSIONES}

La independencia del poder judicial no resulta la cuestión más importante, lo trascendental recae en la independencia en el ejercicio de la función jurisdiccional.

La reforma del mecanismo de ejercicio de la función judicial no constituye una reforma aislada, requiere un avance sincronizado de la reforma de la gestión de los recursos humanos dentro de la actividad judicial, de la reforma del mecanismo de formación de los jueces, de la reforma de la gestión administrativa y de la reforma del sistema de garantía para los profesional de este sector, para así alcanzar su éxito final.

Es cierto que la aplicación y eficacia de toda esta gama de reformas tomará algún tiempo y es oportuno señalar que, aunque importantes, estas medidas de apoyo no son el objetivo final de la reforma. Sólo cuando las actividades judiciales funcionan de acuerdo con las normas jurídicas y se establece el mecanismo científico de ejercicio de la jurisdicción, se puede garantizar la justicia. 


\section{BIBLIOGRAFÍA}

- ALLIENDE, Jaime del Valle. "El fortalecimiento del Poder Judicial Chileno."EN: Revista Chilena de Derecho, Vol. 15, No. 1, enero-abril 1988.

- ANDRÉS IBÁÑEZ, Perfecto. Poder judicial y juez en el Estado constitucional de Derecho. El sistema del Consejo en La experiencia jurisdiccional: Del Estado legislativo de Derecho al Estado constitucional de Derecho. Madrid, Consejo General del Poder Judicial, 1999.

- BORDALÍ SALAMANCA, Andrés. "La doctrina de la separación de poderes y el poder judicial chileno". EN: Revista de Derecho de la Pontificia Universidad Católica de Valparaíso, Valparaíso, Chile, 1er Semestre 2008, p. 197.

- BUSCAGLIA, Edgardo. "Poder Judicial, Reforma Judicial y Democracia." EN: Contexto. Revista de Derecho y Economia, Vol. 1, enero 1998.

- DUGUIT, Leon. Manual de Derecho Constitucional, Granada, Editorial Comares, 2005.

- EGANA, Jose Luis Cea . "Reforma Constitucional al Poder Judicial". EN: Revista Chilena de Derecho, Vol. 18, septiembrediciembre 1991, Santiago de Chile.

- FIORAVANTI, Maurizio. EN: Maurizio Fioravanti et al. (Coordinador). El Estado moderno en Europa. Instituciones y Derecho (traducción castellana de M. Martínez Neira). Madrid, Editorial Trotta, 2004.

- LASCANO, David. "Teoria de Jurisdicción". EN: Revista General de Derecho y Jurisprudencia, Vol. 1, 1930,

- MORTARA, Lodovico. Lo Stato moderno e la giustizia. Napoli, Edizioni Scientifiche Italiane, 1992.

- LEONHARD, Alan T. "El Constitucionalismo y el Poder Judicial Argentino". EN: InterAmerican Law Review, Vol. 8, 1966.

- MONTESQUIEU. "El espíritu de las leyes". Madrid, Biblioteca Auxiliar del Jurisconsulto y Publicista, 1845.

- NAVARRETE, Jaime B. "El Poder del Poder Judicial". EN: Revista Chilena de Derecho, Vol. 1, febrero 1974, Santiago de Chile.

- PEDRAZ, Ernesto. Constitución, jurisdicción y proceso. Madrid, Ediciones Akal, 1990.

- VELANDIA PAEZ, Didimo. "La Independencia Judicial y su Relacion con el órgano legislativo." EN: Saint Louis University Law Journal, Vol. 42, No. 4, 1998.

- ZAFFARONI, Eugenio Raul y Lucila Larrandart. "Administracion de Justicia y Reforma Constitucional en la Argentina: La Necesidad de un Modelo". EN: Derecho Penal y Criminologia, Vol. 8, Nos. 27-28, septiembre 1985- diciembre 1985; enero 1986 - abril 1986. 